\title{
Calculation of a crimping point shear resistance for steel sheet piles based on a calibrated numerical model
}

\author{
J. Vande Voorde \\ ArcelorMittal R\&D Industry Gent, Zelzate, Belgium \\ P. El Boueiz \& A. Glorieux \\ ArcelorMittal Global $R \&$ D Belval \& Differdange, Esch-sur-Alzette, Luxembourg \\ J. Martins \\ ArcelorMittal Commercial RPS Sàrl, Esch-sur-Alzette, Luxembourg
}

\begin{abstract}
As the interlock of $U$ type ArcelorMittal steel sheet pile wall is located on the neutral axis, where the shear stress is maximum, it is very important that the connection is solid and strong enough to transfer the shear stress from one pile to the other. A solution is to crimp the interlock to guarantee the shear force transmission. Nowadays the shear resistance of the crimped sheet piles is limited by the power of the crimping press and the occurrence of cracks in the crimped areas. Furthermore, the value can only be obtained by mechanical testing, which should be performed for each sheet pile profile. ArcelorMittal R\&D developed a numerical model that simulates the crimping mechanism, as well as the shear (compression) test used to determine the shear resistance and stiffness. This Abaqus ${ }^{\circledR}$ model was calibrated and validated using a wide range of experimental data of crimping tests and compression tests performed at the mills in Belval (LU) and Dabrowa (PL). Based on numerous numerical results, correlations were developed and verified between the different influencing parameters and the effectiveness of the tool (crimping force, tool displacement, final depth of the crimped point, shear force, tool massiveness......). These formulas present a simplified method to calculate the shear resistance of each performed crimping point along the sheet pile length.
\end{abstract}

\section{INTRODUCTION}

U-type ArcelorMittal steel sheet piles are usually driven as double or triple piles (Figure 1). As the common Larssen interlock is on the neutral axis, it is important to ensure the shear stress transfer through the connection. The common interlock should then be solidarized, otherwise reduction factors according to the EN 1993-5 will be applied, implying a bending resistance reduction up to $50 \%$. The wall would also allow unwanted oblique bending.

The standard solution is to crimp the common interlock in such a way that it guarantees the transmission of the shear force through the interlock. In this way two single U piles act as one double pile. Thus, the mechanical properties of a sheet pile wall, built-up of double $U$ piles, generally come very close to the properties of the continuous wall. The crimping point should satisfy the stiffness and shear resistance level as defined in the German design recommendations EAU, determined by mechanical tests until now. The shear resistance at $5 \mathrm{~mm}$ of displacement should be at least $75 \mathrm{kN} /$ point, which implies a minimum required stiffness of 15 $\mathrm{kN} / \mathrm{mm} / \mathrm{pt}$. EN 1993-5 and prEN 10248 (Annex E) will allow a $10 \mathrm{~mm}$ displacement for the ultimate resistance of the crimps. 

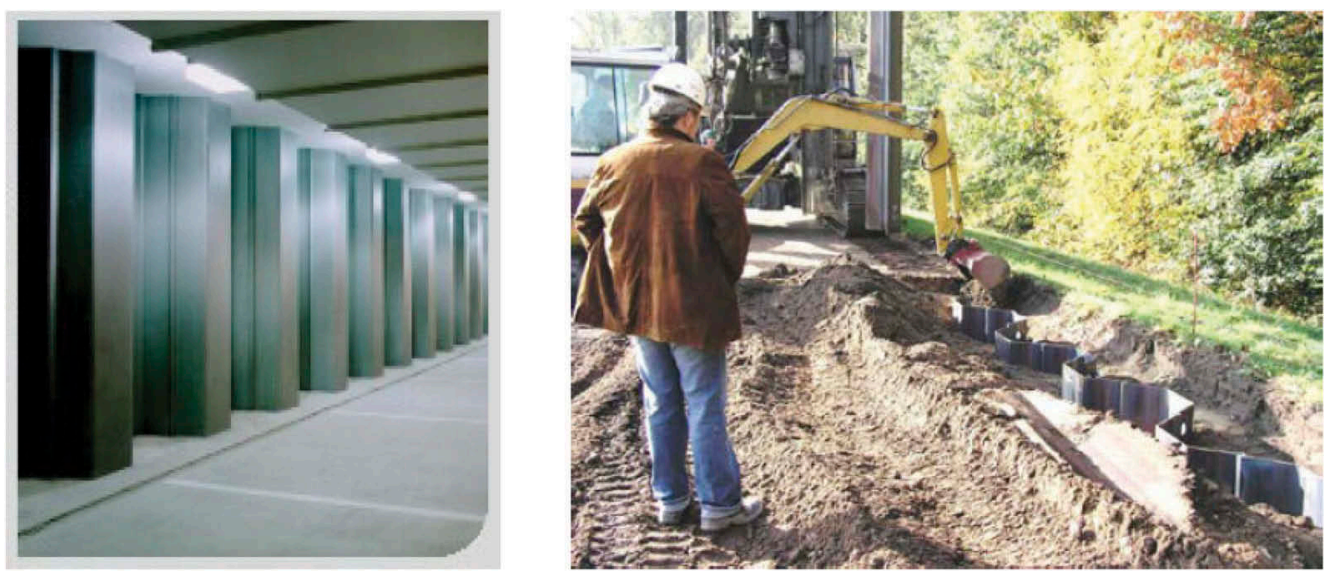

Figure 1. Examples of U sheet pile wall.

The following article details the development of an Abaqus ${ }^{\circledR}$ numerical model to simulate both the crimping mechanism and the compression test used for determination of shear resistance and stiffness. The numerical models were calibrated based on previous mechanical tests performed in ArcelorMittal Belval (LU) and Dabrowa (PL) mills. This will allow a theoretical definition of the crimping points characterization and of the role of the different parameters (including but not limited to the crimping force, the sheet pile material, the interlock geometry and the tool geometry).

Defining the crimping resistance theoretically avoids large tests campaign and provide savings in terms of cost and time. Having such correlations will allow to calculate a lot of crimping configurations considering a large amount of parameters. It becomes thus possible to optimise the crimping process knowing the limitations of the available crimping machine and tool geometry.

\section{ABAQUS $^{\circledR}$ FINITE ELEMENT MODELING DEVELOPMENT}

\subsection{Outlook}

The crimping is performed at ArcelorMittal production site with a press capable of driving a 3-headed tool into the interlocking part of two sheet piles with a force of up to 280 Tonnes. The result is a triple clinch-like forged deformation holding both sheet piles together. The connection has to withstand the shear forces occurring when the sheet piles are driven into position. A compression test is prescribed to test this shear resistance. The crimped interlock section is subjected to (shear) compression while the displacement and the compression force are logged (Figure 2). The by standard prescribed minimum strength is $75 \mathrm{kN}$ at $5 \mathrm{~mm}$ displacement per crimped point.

\subsection{Experimental data}

The logged data of crimping campaigns performed from 2008 until 2016 on a PU32 profile, was provided by ArcelorMittal Global R\&D. The data includes the position of the crimping cylinders and the forces they exercise as a function of time, as well as the final depth of the crimped points. The data covered additionally geometric measurements and material properties. 

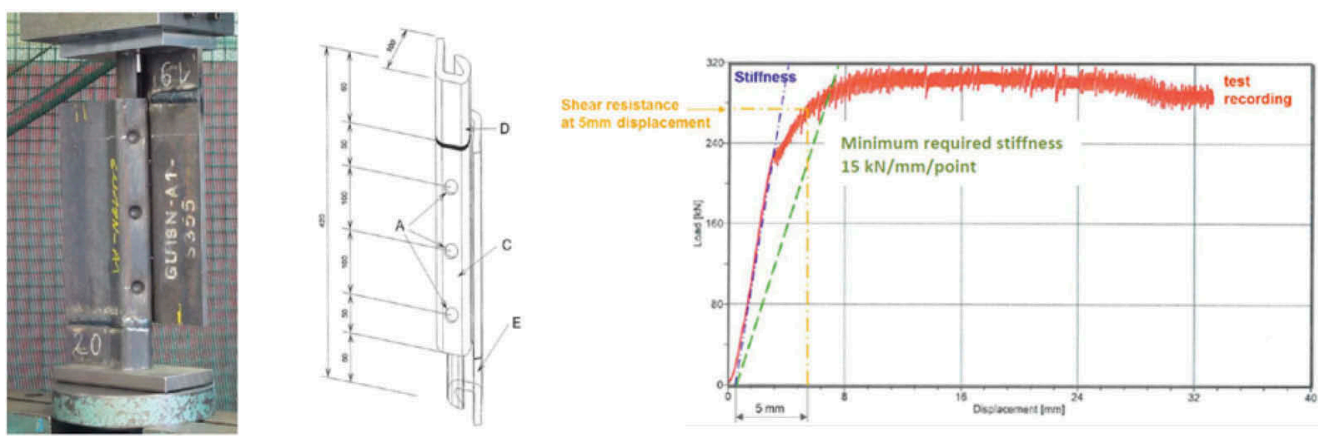

Figure 2. Shear compression test set-up with data log and minimum requirement (scheme of crimping point from prEN 10248).

\subsection{Numerical simulation}

In this section the methodology to perform simulations of the crimping process and the shear compression test is detailed. The output of the crimping simulation is used as input for the shear compression test to account for deformation and strengthening of the material. Therefore, this simulation is treated first.

The crimping is done by pressing a triple tool into the sheet pile interlocks. The sheet pile is supported by an anvil. Its position relative to the zero plane is named dYS. The displacement of the tools during the contact is called $\mathrm{dYC}$. The final crimping depth after retreat of the tools (and spring back) is called FD and the maximum crimping force FC.

The area around the crimping points, is meshed with $3 \mathrm{D}$ elements. The rest of the sheet pile is meshed with shell elements which are connected to the local area model using shell-to-solid coupling. The material behavior is elasto-plastic with a steel grade S $430 \mathrm{GP}$, while the tools are modelled purely elastic. Boundary conditions are applied to the ends of the sheets: symmetry on one end and pinned on the other (Figure 3).

The normal contact definition is "hard" (meaning any overlap is countered by a penalty force) and a tangential friction coefficient is prescribed. The friction coefficient of 0.2 was used in the simulations. To ensure that this choice won't have influence on the model calibration, simulations with coefficients from 0.1 to 0.3 showed that this coefficient has a negligible effect on the result.

The full sheet pile model allows including the influence of gravity and the twisting of the sheet piles during the crimping process.

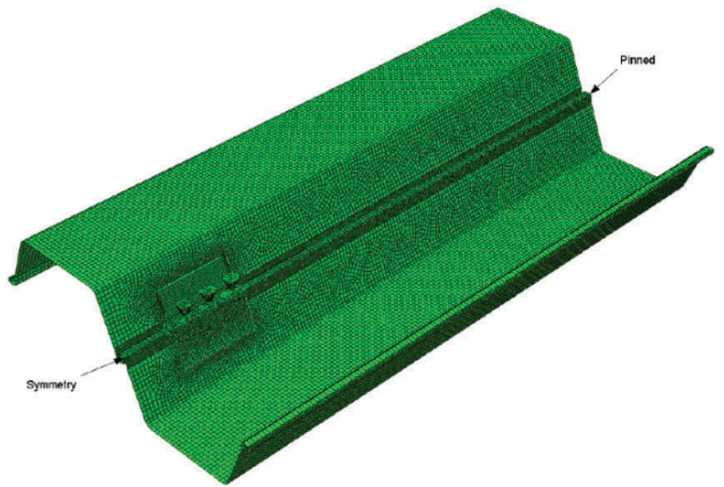

Figure 3. Full sheet pile model mesh with boundary conditions. 


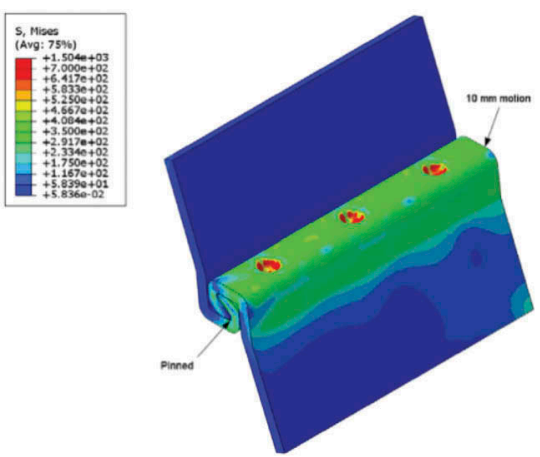

Figure 4. Initial conditions for the shear test simulation.

The shear compression test is modelled by taking the deformed local crimping area from the crimping simulation, including the residual stresses and the work hardening of the material, and subjecting it to a prescribed displacement of $10 \mathrm{~mm}$, as defined by the standard and illustrated in Figure 2 in section 2.1. The deformation, hardening and residual stresses of the crimping operation are included at the start of the simulation (Figure 4). The front of the bottom sheet is pinned, while a translation of $10 \mathrm{~mm}$ is prescribed at the end of the top sheet.

\section{RESULTS AND MODEL CALIBRATION}

In this section the simulation methodology is validated against experimental data from 2016 testing campaign, by referring to an average chosen point. The true interlock geometry as well as the material data derived from the tensile test was used to numerically reproduce the test result.

The simulation crimping curve is compared to the experimental value (Figure 5). The calculated final depth of $13.67 \mathrm{~mm}$ is almost identical to the experimental value of $13.37 \mathrm{~mm}$. In addition, the sheet pile behaviour is similar in terms of stiffness to the test result. This model can therefore be considered fully, qualitatively and quantitively, validated for the crimping simulation.

In Figure 6 below, a few simulation results are compared to the experimental data in the form of compression curves (only one full compression curve was provided). It is clear that the shearphnomenon is captured well, both qualitatively and quantitatively.

\section{CORRELATIONS WITH CRIMPING PARAMETERS}

Results of the crimping operation and compression shear test depend on several input parameters (for instance adherence to geometric tolerances). In this section, the simulations results are used to correlate the maximum crimping force FC, the final crimping depth FD and the shear force at $5 \mathrm{~mm}$ compression $\mathrm{F} \_5 \mathrm{~mm}$ or $\mathrm{F} 5$ to various parameters. These correlations can then be used for fine-tuning of the real process.

\subsection{Design of experiments}

The effect of the following parameters will be studied:

a) Crimping tool displacement dYC: Depth of the crimping, ranged from 13 to $18 \mathrm{~mm}$

b) Position of the support anvil dYS: Amount of the lifting, ranged from -4 to $4 \mathrm{~mm}$ 


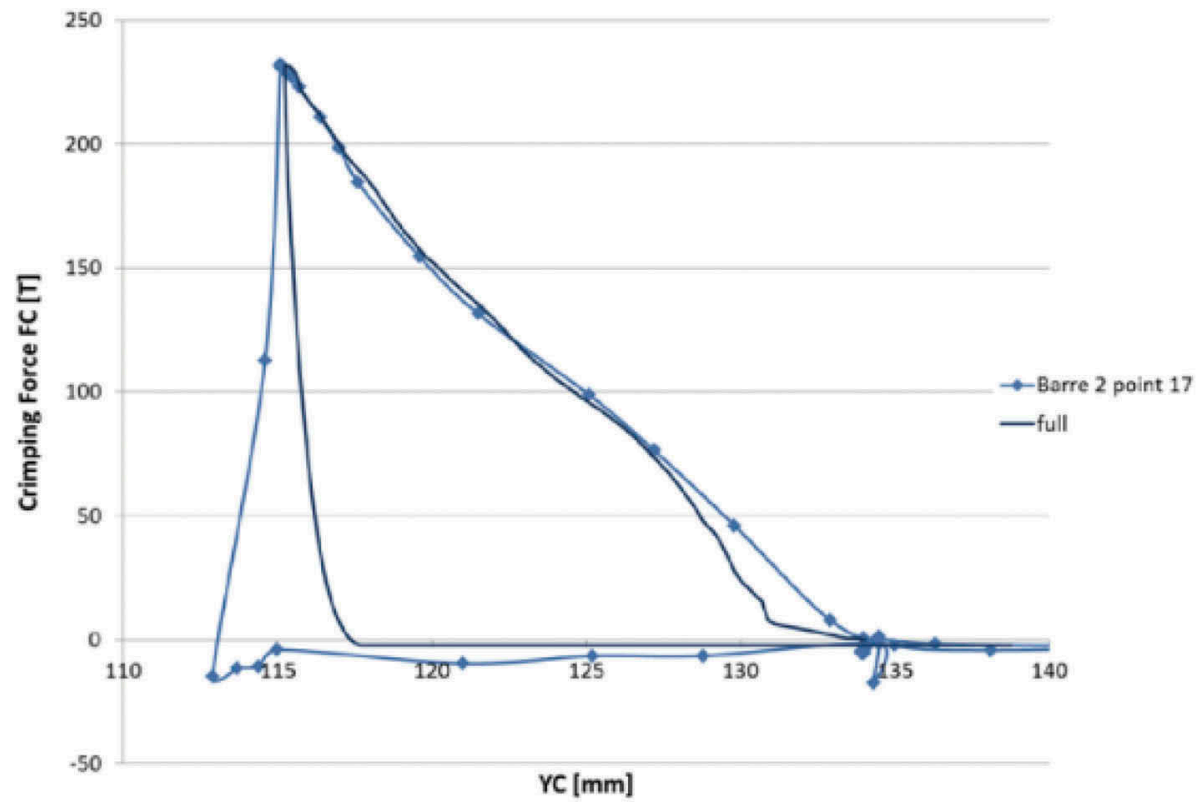

Figure 5. Crimping curves: comparison of full sheet model results to experimental data.

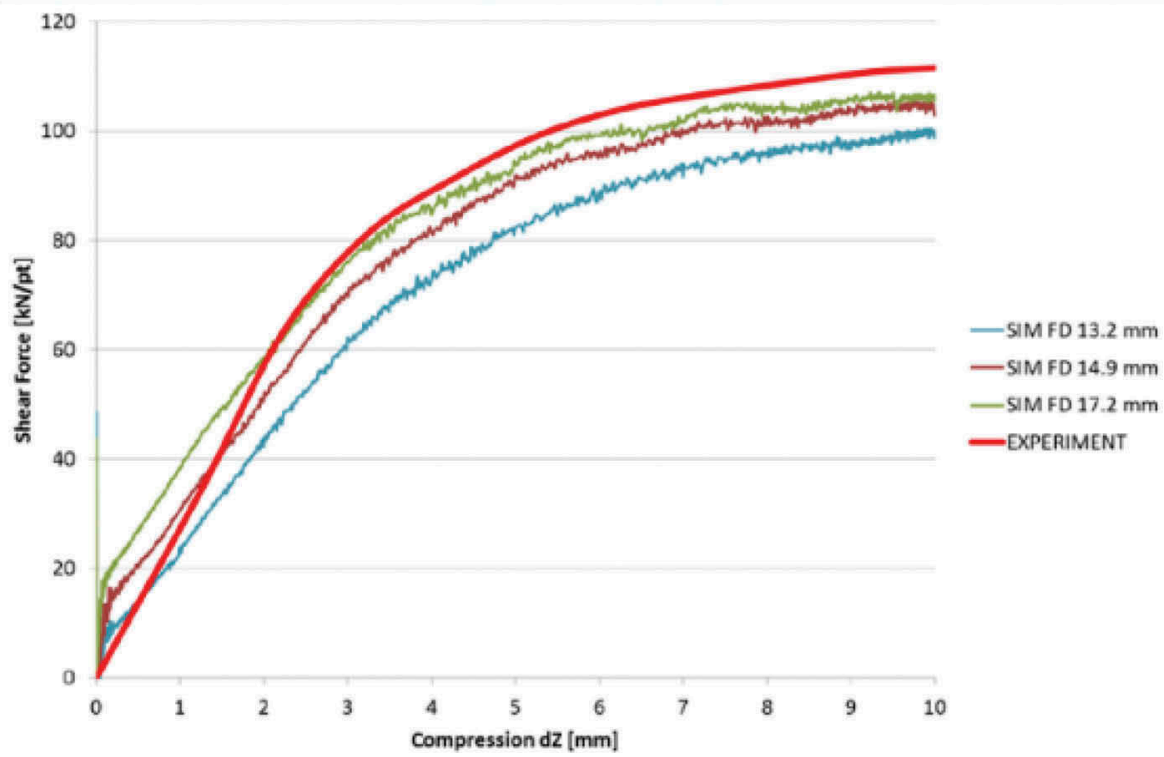

Figure 6. Comparison of simulated shear force curves to experimental data (heavy line).

c) Material properties: yield point Re and strengthening capacity $n$ : Definition of a straight tensile curve by defining stress at yield $(\mathrm{Re})$ and at $100 \%$ strain $(\mathrm{Re}+\mathrm{n})$, ranged from 400 to $600 \mathrm{MPa}$ for Re and from 500 to $2500 \mathrm{MPA}$ for $\mathrm{n}$.

d) Geometry of the sheet pile interlocks: SheetFullness, ranged from 0.9 to 1.0 of the nominal dimensions.

e) Massiveness of the tool: scale. This parameter depends on the tool shape. Ranged from 0.5 (slender) to 2.0 (massive). A value of 1.0 corresponds to the current tool. 


\subsection{Correlations}

In the following section, only the most important conclusions are treated.

The final depth FD is correlated very strongly to the tool displacement dYC (Figure 7). The position of the support anvil dYS and the material are the only other parameters who have a minor influence on the final depth. For the maximum crimping force FC and the shear force F_5mm such strong singly determined correlations don't exist. The strongest correlations are FC(FD) and F5(FC). Both parameters are linearly correlated with both the final depth FD and the sheetFullness.

The position of the support anvil has a complicated, but significant influence on FC and F_5mm and even on FD (as a rare parameter apart from dYC). The results relate linearly to dYS for negative values, but strongly non-linearly for positive values.

Understandably the strength of the material has an influence on the crimping force FC and the shear force F_5mm. Due to springback it also a non-linear has an influence on the final depth FD.

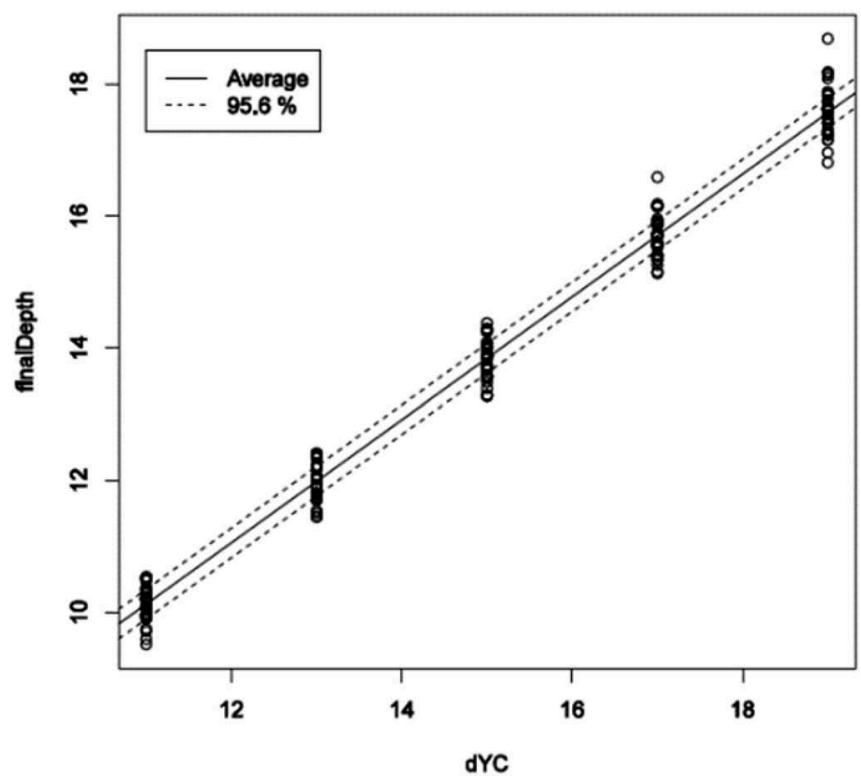

Figure 7. Correlation of finalDepth with dYC.

The derived correlations are summarized in the Table 1 below.

Table 1. Summary of the derived correlations.

\begin{tabular}{ll}
\hline Parameter & Correlation \\
\hline & $F D=-0.1085+0.93 \times d Y C$ \\
& $F D=1.332+0.758 \times d Y C-0.223 \times \mathrm{dYS}-0.022 \times d Y C \times$ \\
& $\mathrm{dYS}+0.0056 \times d Y C^{2}+0.0086 \times d Y C^{2}+0.0097 \times d Y S^{2} \times$ \\
& $d Y C+0.00056 \times d Y C^{2} \times d Y C-0.00035 \times d Y C^{2} \times d Y S^{2}$ \\
& $F D=0.314+0.961 \times d Y C-3.4 \times 10^{-4} \times R e-2.648 \times 10^{-4} \times$ \\
& $n+5.426 \times 10^{-8} \times n^{2}-4.103 \times 10^{-6} \times d Y C \times R e-2.068 \times$ \\
& $10^{-5} \times d Y C \times n+1.297 \times 10^{-7} \times R e \times n$
\end{tabular}


Table 1. (Continued)

\begin{tabular}{|c|c|c|}
\hline Parameter & Correlation & \\
\hline \multirow{3}{*}{$\mathrm{FC}$} & $\begin{array}{l}F C=-9.552 \times F D+31.641 \times F D \times \text { sheetFullness }+31.778 \\
\times \text { sheetFullness }-88.086\end{array}$ & (4) \\
\hline & $\begin{array}{l}F C=10.55+11.69 \times d Y C+16.23 \times d Y S-2.63 \times d Y C \times \\
d Y S+0.291 \times d Y C^{2}+0.203 \times d Y S^{2}+0.199 \times d Y S^{2} \times \\
d Y C+0.0688 \times d Y C^{2} \times d Y S-0.0137 \times d Y C^{2} \times d Y S^{2}\end{array}$ & (5) \\
\hline & $\begin{array}{l}F C=-9.58+1.434 \times d Y C+1.38 \times 10^{-2} \times R e-2.889 \times 10^{-} \\
2 \times n+3.991 \times 10^{-2} \times n^{2}+1.837 \times 10^{-2} \times d Y C \times R e+6.239 \\
\times 10^{-2} \times d Y C \times n+8.431 \times 10^{-2} \times R e \times n\end{array}$ & (6) \\
\hline \multirow{3}{*}{$\mathrm{FC}$} & $\begin{array}{l}F \_5 \mathrm{~mm}=22.046 \times F D-8.942 \times F D \times \text { sheetFullness }+ \\
384.518 \times \text { sheetFullness }-460.676\end{array}$ & (7) \\
\hline & $\begin{array}{l}F 5=-56.14+9.35 \times d Y C+4.25 \times d Y S-0.346 \times d Y C \times \\
d Y S+0.0401 \times d Y C^{2}+7.7 \times d Y S^{2}-1.06 \times d Y S^{2} \times d Y C+ \\
0.00152 \times d Y C^{2} \times d Y S+0.0358 \times d Y C^{2} \times d Y S^{2}\end{array}$ & (8) \\
\hline & $\begin{array}{l}F_{-} 5 \mathrm{~mm}=-22.3+3.5 \times d Y C-0.0913 \times R e+0.00264 \times n- \\
3.63 \times 10^{-6} \times \mathrm{n}^{2}+0.0125 \times d Y C \times R e+0.00144 \times d Y C \times \\
n-3.12 \times 10^{\wedge-7} \times \operatorname{Re} \times n\end{array}$ & (9) \\
\hline
\end{tabular}

Where:

FD: $\quad$ Final crimping depth

FC: $\quad$ Crimping force

F_5mm: Compression shear force @ $5 \mathrm{~mm}$ displacement

dYC: $\quad$ Crimping displacement

dYS: $\quad$ Position of the lower anvil vs zero plane

Re: $\quad$ Yield point of the sheet pile material

$\mathrm{N}$ : $\quad$ Strengthening of the material

sheetFullness: Factor describing the sheet pile interlock thickness

\section{CONCLUSIONS}

In this paper, a sheet pile crimping simulation methodology, as performed in ArcelorMittal Belval plant, and the subsequent compression shear test is presented. The model was validated against experimental data provided by AM Global R\&D. This model was used to set up correlations between the crimping performance (such as the required crimping force and the shear resistance in the compression force) and various parameters of the crimping process. These correlations can now be used in the factory line to perform the current crimping under optimum circumstances, as well as to calculate numerically the crimping point characteristics, that is nowadays only possible with mechanical tests. Moreover, the study highlighted the most influencing parameters of the crimping process on the crimping resistance, allowing to target precisely the optimization.

\section{REFERENCES}

EAU (2012): Recommendations of the Committee for Waterfront Structures Harbours and Waterways EAU 2012, Ernst \& Sohn.

EN 1993-5, Eurocode 3: Design of steel structures - Part 5: Piling, Feb 2007.

prEN 10248-1: Hot-rolled steel sheet piling - Part 1: Technical delivery conditions, March 2006. 